\title{
PATTERN OF ANTENATAL CARE AMONG WOMEN UTILISING A TERTIARY CARE CENTRE IN GOVERNMENT SECTOR FOR DELIVERY
}

\author{
Mini C. $H^{1}$, Mohammed Sidhiq ${ }^{2}$
}

${ }_{1}^{1}$ Professor, Department of Obstetrics and Gynaecology, Government Medical College, Kozhikode.

${ }^{2}$ Assistant Professor, Department of Obstetrics and Gynaecology, Government Medical College, Kozhikode.

ABSTRACT

\section{BACKGROUND}

The goal of antenatal care is to prevent, detect and alleviate or manage the health problems in pregnancy. Kerala had a Maternal Mortality Ratio of 61 in 2011-13 which is well below the target set in Millennium Development Goal. We studied the antenatal services utilised by the women. Aims-1. To look into the pattern of antenatal care and patient preferences in antenatal contacts. 2 . To study the determinants of utilisation of government or private services.

\section{MATERIALS AND METHODS}

Study subjects - 200 antenatal women, after 36 weeks of pregnancy admitted for delivery. There were 276 women referred from outside hospitals. 76 women had serious maternal complications. Hence, they were excluded. So the sample size was 200.

Setting - Department of OBG in Govt. Medical College, Kozhikode.

Period - One month (March 2017).

Design - This was a cross sectional descriptive study.

Data collection - All the women were interviewed with a pre-structured questionnaire and information collected by trained doctors. The women who had antenatal check-ups at government institutions were considered under govt. sector and women who were seen by obstetricians at private clinics or hospitals were included in the private sector.

\section{RESULTS}

Out of 200 women, $68.5 \%$ belonged to $20-30$ years. $6 \%$ were below 19 and $9 \%$ were aged $>35.61 \%$ resided in the same district where the hospital is situated. Regarding ANC, 98\% registered early. All patients had more than 8 visits, consumed IFA tablets and took tetanus immunisation. 82 women had private antenatal visits. The family income and education were significantly higher in this group with a $p$ value of 0.0012 and $p$ value of 0.0003 respectively.

\section{CONCLUSION}

Our study showed that in Kerala, women are aware of antenatal services and utilised it efficiently. Women with higher income and education preferred private consultations but opted a well-equipped centre for delivery.

\section{KEYWORDS}

Antenatal Care, Government Maternal Health Services, Institutional Deliveries, Preference of Women.

HOW TO CITE THIS ARTICLE: Mini CH, Sidhiq M. Pattern of antenatal care among women utilising a tertiary care centre in government sector for delivery. J. Evolution Med. Dent. Sci. 2017;6(51):3878-3881, DOI: 10.14260/Jemds/2017/838

\begin{abstract}
BACKGROUND
Antenatal care is the continuum of care given to a woman during pregnancy and childbirth. The goal of antenatal care is to prevent, detect and alleviate or manage the health problems in pregnancy. This can be of two types. 1. Complication of pregnancy itself. 2. Pre-existing conditions that worsen during pregnancy. An effective antenatal care package depends on competent health care providers in a functioning health system with timely referral services. Even now, 120 women die of causes associated with pregnancy, in a day, in India. However, the benefits of antenatal care are greater than mortality reduction alone. Grouping pregnant
\end{abstract}

Financial or Other, Competing Interest: None.

Submission 22-05-2017, Peer Review 14-06-2017,

Acceptance 20-06-2017, Published 24-06-2017.

Corresponding Author:

Dr. Mini C. H,

Professor,

Department of $O B G$,

Government Medical College,

Kozhikode-673655, Kerala.

E-mail: drminichvijaya@yahoo.co.in

DOI: $10.14260 /$ jemds $/ 2017 / 838$ women into low risk and high risk to determine the type of delivery services needed can reduce the morbidity to a great extent. Hence, a referral institution caters to high risk pregnancies and uncomplicated women in the nearby population. Globally only $85 \%$ of women have access to antenatal care of which only $58 \%$ receive at least 4 visits. In India, Maternal Mortality Ratio (MMR) was 178 in 2011-13.1-3

The goal was to reduce it to 109. Kerala had a MMR of 61 in 2011-13 which was well below the target. This is achieved through maternal health programmes in Government and private sectors. The women view antenatal visits as a source of knowledge, information and clinical expertise and they generally appreciate the tests and advice they are offered.

In the present study, we tried to understand the antenatal services given, adherence to visits and selection of the delivery services.

\section{Aims}

1. To look into the pattern of antenatal care and patient preferences in antenatal contacts.

2. To study the determinants of utilisation of government or private services. 


\section{MATERIALS AND METHODS \\ Study Subjects}

Antenatal women, after 36 weeks of pregnancy who were referred to our hospital for delivery were included in the study.

\section{Sample Size}

There were 276 women in the study period. Seventy-six women had serious maternal complications and excluded. Hence, the sample size was 200 .

\section{Setting}

Department of Obstetrics and Gynaecology in Govt. Medical College, Kozhikode. Period - one month (March 2017).

\section{Design}

A cross sectional descriptive study.

\section{Data Collection}

Antenatal women who had check-ups from other hospitals including government and private sector were included after obtaining willingness. Women who were seen at Government run community health centres, Taluk headquarters hospital and District hospital were included in the Government sector. Women who had antenatal check-ups at private clinics or hospitals were included in the private sector.

\section{Exclusion Criteria}

Women with serious medical or obstetric complications were excluded.

\section{Method}

A questionnaire was prepared and information collected by direct interview by trained doctors. Sociodemographic data like Age, Parity, Educational level and monthly income, Place of residence were noted. Details of first visit, and subsequent antenatal check-ups, usage of government or private services, were noted. Subjects were divided into 3 groups according to monthly income as -Rs 1802-8988 (L), Rs 8989 - 17998 (M) and $>17999$ as high income. ${ }^{4}$ The women were divided into 3 categories according to educational level as SSLC, HSE and above. Details of immunisation was collected. Awareness about blood investigations noted. The number and gestational age at which ultrasonogram was done was taken. Preferences in selecting the centre noted. Complications in the previous and present pregnancy were taken.

\section{Data Analysis}

Data was analysed by Epi info software. Data was expressed by frequency and percentages. Statistical analysis was done using chi-square test. A two-tailed $\mathrm{p}$ value $<0.05$ was considered to indicate statistical significance.

\section{RESULTS}

Age is shown in Table 1.

\begin{tabular}{|c|c|c|}
\hline Age in Years & Number & \% \\
\hline$<19$ & 12 & 6 \\
\hline $20-24$ & 66 & 33 \\
\hline
\end{tabular}

\begin{tabular}{|c|c|c|}
\hline $25-29$ & 71 & 35.5 \\
\hline $30-34$ & 33 & 16.5 \\
\hline$>35$ & 18 & 9 \\
\hline \multicolumn{2}{|c|}{ Table 1. Shows Age in Different Groups } \\
\hline
\end{tabular}

All the women were below 40 years. Parity - There were 75 primigravidae and 125 multigravidae. Place of residenceKozhikode- 122 (61\%), Malappuram- 58 (29\%), Wayanad -10 (5\%), Kannur -4 (2\%), Palakkad - 4 (2\%), Kollam -2 (1\%)

Education of women - Among the women, 104 (52\%) had studied up to SSLC. 76 (38\%) had higher secondary education and $20(10 \%)$ completed diploma or degree.

Income- The study subjects were divided in three groups according to the income. Low income group constituted the majority with 118 (59\%). Middle income women were 71 (35.5\%) and a small group (5.5\%) had high income.

Antenatal check-ups - All women (100\%) had regular antenatal visits. Average number was 8 . The number of women who had consultation in Government institutions were 118 (59\%) and in private centres were 82 (41\%).

Period of gestation at first visit- $99 \%$ of women were seen by a consultant in the first trimester. Only 2 (1\%) had their first ANC in the second trimester.

Immunisation - 100\% of women were fully immunised against tetanus.

Investigations - Blood investigations were done along with check-ups. Haemoglobin Group \& Rh Type, Urine -RE, Screening tests for VDRL, HIV, HBsAg and Diabetes.

Ultrasonogram - 198 (99\%) women were seen in the first trimester and ultrasonogram was taken for confirmation and dating of pregnancy.

Two patients had first visit at early $2^{\text {nd }}$ trimester. Second trimester and third trimester USG was done by all (100\%) patients.

Iron and Folic acid therapy - 124 (62\%) women consumed the government supplied tablets, and 76 (38\%) bought tablets from medical shops.

We took Age, Parity, education and Income as variables to determine the utilisation of government versus private sector. The results are shown in Tables 2, 3, 4 and 5.

\begin{tabular}{|c|c|c|c|}
\hline Age & Govt. & Private & Total \\
\hline$<19$ & $8(66.7 \%)$ & $4(33.3 \%)$ & $12(100 \%)$ \\
\hline $20-24$ & $33(50 \%)$ & $33(50 \%)$ & $66(100 \%)$ \\
\hline $25-29$ & $43(60.6 \%)$ & $28(39.4 \%)$ & $71(100 \%)$ \\
\hline $30-35$ & $20(60.7 \%)$ & $13(39.3 \%)$ & $33(100 \%)$ \\
\hline$>35$ & $14(77.7 \%)$ & $4(22.3 \%)$ & $18(100 \%)$ \\
\hline Total & $118(59 \%)$ & $82(41 \%)$ & $\mathbf{2 0 0 ( 1 0 0 \% )}$ \\
\hline Table 2. Age, Compared in Government and Private Sector \\
\hline
\end{tabular}

In Table 2, age of the patient in government and private sectors is shown. There was no statistically significant difference between age groups since p value was 0.264 .

\begin{tabular}{|c|c|c|c|}
\hline Parity & Govt. & Private & Total \\
\hline Primi & $40(53.3 \%)$ & $35(46,7 \%)$ & $75(100 \%)$ \\
\hline Multi & $75(62.5 \%)$ & $45(37.5 \%)$ & $120(100 \%)$ \\
\hline Grand multi & $3(60 \%)$ & $2(40 \%)$ & $5(100 \%)$ \\
\hline Total & $\mathbf{1 1 8}(59 \%)$ & $\mathbf{8 2}(41 \%)$ & $\mathbf{2 0 0}(\mathbf{1 0 0} \%)$ \\
\hline Table 3. Parity, Compared in Government and Private \\
\hline
\end{tabular}


Sector

In Table 3, comparison is done with parity. The results showed no significant relation as $\mathrm{p}$ value $=0.448$, was not significant.

\begin{tabular}{|c|c|c|c|}
\hline Studied Up to & Govt. & Private & Total \\
\hline SSLC & $71(68.2 \%)$ & $33(31.7 \%)$ & $104(100 \%)$ \\
\hline $12^{\text {th }}$ std. & $43(56.6 \%)$ & $33(43.4 \%)$ & $76(100 \%)$ \\
\hline Degree & $4(20 \%)$ & $16(80 \%)$ & $20(100 \%)$ \\
\hline Total & $118(59 \%)$ & $\mathbf{8 2}(41 \%)$ & $\mathbf{2 0 0}(\mathbf{1 0 0} \%)$ \\
\hline \multicolumn{4}{|c|}{ Table 4. Educational Level in Government and } \\
Private Sector \\
\hline
\end{tabular}

Table. 4 shows the education in two groups. It was seen that there was difference in selection of hospital. P value was 0.0003 which was statistically significant and showed that educated women preferred private health care facility.

\begin{tabular}{|c|c|c|c|}
\hline Group & Govt. & Private & Total \\
\hline High & $1(9 \%)$ & $10(91 \%)$ & $11(100 \%)$ \\
\hline Middle & $40(56.3 \%)$ & $31(43.7 \%)$ & $71(100 \%)$ \\
\hline Low & $77(65.2 \%)$ & $41(34.8 \%)$ & $118(100 \%)$ \\
\hline Total & $118(59 \%)$ & $82(41 \%)$ & $200(100 \%)$ \\
\hline Table 5. Income Groups Compared in Government and \\
Private Sector \\
\hline
\end{tabular}

Women with high income utilised private sector services more in comparison with others with a p value of 0.0012 which was statistically significant. This is shown in Table. 5.

\section{DISCUSSION}

This study was done in the state of Kerala. The state has a very good network of maternal and child health services both in the government and private. We selected 200 antenatal women. All were married and above 19 years. Maximum age was 40 years.

In the study by Srilatha et al in Thiruvananthapuram in $2002,80 \%$ of pregnant women belonged to 20-30 years, $12.4 \%$ were $<19$ and $7.2 \%$ were $>30$ years 5 . In our study, younger women were less and older were more. This showed that age of marriage has gone up in the last 15 years. As the assisted reproductive treatments increase we are more likely to get elderly women with pregnancy.

Studies from other states show similar data. RK Gupta from Kashmir had shown a mean age of 26 years. ${ }^{6}$ BB Patel gave a mean age of 24.2 years, ${ }^{7}$ MP Roy from Lucknow reported that $50 \%$ of patients were 26 years. ${ }^{8}$ Adolescent pregnancies, tend to have more complications. V Kumar reported an incidence of $8.3-24 \%$ in India, and said more than $10 \%$ did not receive antenatal care. ${ }^{9}$ Seneesh from Gujarat showed an incidence of $2.8 \% .{ }^{10}$ PK Singh reported an incidence of $16.4 \%$ illiterates among adolescents. ${ }^{11}$ Our results were comparable to others in the incidence. But we did not have any woman less than 19 years.

Srilatha had given an equal number of primigravidae and multigravidae. ${ }^{5}$ We had less number of primigravidae. In the multigravidae, $40 \%$ had complication in the previous pregnancy. Navaneetham reported a higher incidence of complications in the previous pregnancy in multigravidae who selected higher institutions for delivery. ${ }^{12}$
The institution is a tertiary centre for 4 districts including remote hilly areas. Majority of the patients belonged to the same district indicating the preference of the patients to the nearby government facility even though many private hospitals are available.

In our study, 59\% belonged to the low income group. This is quite understandable since this is a government institution. A small group (5.5\%) belonged to high income status. This may be patients with high risk pregnancy who needed multidisciplinary team work. Such facilities are available round the clock which made them opt this hospital. MP Roy reported that $79.3 \%$ deliveries occurred in Government hospitals in Lucknow. ${ }^{8}$ Those women belonged to low socioeconomic status and were late registrants.

All our patients were educated at least to the school level. Navaneetham has reported in his study that illiterates were $10 \%$ in Kerala in 2002. PK Singh had shown $16.4 \%$ illiterates in South India. ${ }^{11}$ The illiteracy rate was $17.5 \%$ in Kashmir and as high as $63.6 \%$ in rural Lucknow.

V Kumar showed that in India $10.3 \%$ of pregnant women had no ANC. ${ }^{9}$ In Kerala it was $0.8 \%$. Navaneetham had seen that in Kerala $91 \%$ women had at least 4 antenatal visits of which $71 \%$ in the first trimester. ${ }^{12}$ A study done by S. Udayan showed that $61 \%$ had poor awareness regarding antenatal investigations. ${ }^{13}$ Our results were comparable to V Kumar. In 2002 , a previous study showed that $42.2 \%$ registered in the first trimester and $7.2 \%$ in the $5^{\text {th }}$ month. ${ }^{5}$ In Tamilnadu, Elaverasan reported early antenatal registration of $69 \%$ women regular intake of IFA by $79 \% .^{14}$ In our study, $41 \%$ women had a private consultation ensuring that continuous care is taken from same doctor. Consultants were obstetricians. Convenient timing, presence of Laboratory facilities and individual attention were the reasons for private ANC.

V Kumar found out that unimmunised women were $6.6 \%$ in India and $5.2 \%$ in Kerala. ${ }^{9}$ But in our study all patients were fully immunised. Previous study also showed 100\% immunisation for tetanus toxoid. Majority used primary health centres for that service.

Iron Folic Acid Tablets (IFA) - According to V Kumar, 9\% did not take IFA in India. In Kerala, it was $4.9 \%$. S. Sumithra also has shown a $98 \%$ intake of IFA. Our study is comparable to this. ${ }^{15}$ In a study from Tamil Nadu it was shown that IFA was taken by $79 \%$ of women.

To achieve the second objective, we used 4 variables. 1 . Age. 2. Parity. 3. Income. 4. Education.

Age of the patient -The distribution of patients in the different age groups were analysed. This was done to see whether young or older women preferred private care. We got a p value of 0.0264 which was not statistically significant.

Parity- Parity was studied to know whether it influenced the choice. Since the p value was 0.0448 it was not significant.

Income- The important decision is taken regarding the institution of delivery as per the family income. Our study showed that high income groups preferred private hospitals. The favourable factors were convenient timing and individual attention. $P$ value $=0.0012$ was statistically significant.

Education- Women who had higher education opted for private care as shown in Table 5. The p value was 0.0003 and statistically significant. This was due to the fact that educated women had jobs contributing to the family income and their opinion mattered in decision making. So they opted for 
private care. This is comparable to the study by MP Roy who reported that a significant relationship was found with age, income, early registration and regular ANC. ${ }^{8}$ Gupta also showed that regular ANC was significantly associated with literacy and SES. 6

\section{CONCLUSION}

The women view antenatal care as a source of knowledge, information and clinical expertise. The importance of early registration and regular antenatal visits is well understood. The selection of institution for delivery is taken considering the factors like reachability, complication in the previous and present pregnancy, and available resources.

\section{REFERENCES}

[1] Millennium development goals India country report2015. MoSPI mospi.nic.in/sites/default/files/publication_reports/ mdg_2july15_1.pdf 2015.

[2] WHO recommendations on antenatal care for a positive pregnancy. apps.who.int/iris/bitstream/10665/250796/1/97892 41549912-eng.pdf 2016.

[3] Dowswell T, Carroli G, Duley L, et al. Alternative versus standard packages of antenatal care for low-risk pregnancy. Cochrane Database of Systematic Reviews 2015;7:CD000934.

[4] Oberoi SS. Updating income ranges for Kuppuswamy's socio-economic status scale for the year 2014. Indian J Public Health 2015;59(2):156-7.

[5] Srilatha S, Remadevi S, Itty L, et al. Assessing the quality of antenatal care in Thiruvananthapuram district. Quality of Antenatal Care 2002:1-39.

[6] Gupta RK, Shora TN, Verma AK, et al. Knowledge regarding antenatal care services, its utilization, and delivery practices in mothers (aged 15-49 years) in a rural area of North India. Tropical Journal of Medical Research 2015;18(2):89-94.
[7] Patel BB, Gurmeet P, Sinalkar DR, et al. A study on knowledge and practices of antenatal care among pregnant women attending antenatal clinic at a tertiary care hospital of Pune, Maharashtra. Medical Journal of Dr DY Patil University 2016;9(3):354-62.

[8] Roy MP, Mohan U, Singh SK, et al. Determinants of utilization of antenatal care services in rural Lucknow, India. Journal of family medicine and primary care 2013;2(1):55-9.

[9] Seneesh KV, Shah M. Feto- maternal outcome in teenage pregnancy-a comparative case control study. J Preg Child Health 2015;2(136).

[10] Navaneetham K, Dharmalingam A. Utilization of maternal health care services in Southern India. Social science \& medicine 2002;55(10):1849-69.

[11] Singh PK, Rai RK, Alagarajan M, et al. Determinants of maternity care services utilization among married adolescents in rural India. PloS one 2012;7(2):e31666.

[12] Kumar V, Singh P. How far is universal coverage of antenatal care (ANC) in India? An evaluation of coverage and expenditure from a national survey. Clinical Epidemiology and Global Health 2017;5(1):17.

[13] Udayan S, Viswanath L, Varghese L. Awareness regarding antenatal investigations among antenatal mothers attending selected tertiary hospital, Kochi, Kerala. Journal of South Asian Federation of Obstetrics \& Gynecology 2014;6(3):129-32.

[14] Elavarasan E, Padhyegurjar MS, Padhyegurjar SB. Cross sectional study of knowledge and awareness among $\mathrm{MCH}$ beneficiaries about antenatal and infant care in rural Tamil Nadu, India. Asian Journal of Medical Sciences 2016;7(1):59-65.

[15] Sumithra S, Aswathy S, Sandeep S, et al. Maternal and child health services utilization in married women of age 15-45 years. Journal of Communicable Diseases 2006;38(1):102. 